\title{
Creep Stress Effect on the Precipitation Behavior of Laves Phase in $\mathrm{Fe}-10 \% \mathrm{Cr}-6 \% \mathrm{~W}$ Alloys
}

\author{
Jie CUI, Ick-Soo KIM, Chang-Yong KANG ${ }^{1)}$ and Kazuya MIYAHARA ${ }^{21}$ \\ Graduate School, Nagoya University, Nagoya 464-8603 Japan. \\ National University, Yong Dang-Dong, Nam-ku, Pusan, Korea. \\ 1) Department of Metallurgical Engineering, Pukyong \\ 2) Department of Molecular Design and Engineering,
} Nagoya University, Nagoya 464-8603 Japan.

(Received on November 9, 2000; accepted in final form on January 19, 2001)

\begin{abstract}
Effect of creep tensile stress on the precipitation behavior of Laves phase in $\mathrm{Fe}-10 \% \mathrm{Cr}-\mathrm{W}$ alloys has been investigated. $\mathrm{Fe}-10 \% \mathrm{Cr}-\mathrm{W}$ alloys are basic alloys of ferritic heat resisting steels, which have been being developed for the ultra-super critical pressure power generating plants. It has been clarified that the creep tensile stress enhances the Laves phase precipitation comparing with that in the same alloys aged under no stress.
\end{abstract}

KEY WORDS: ferritic heat resisting steel; Laves phase; tungsten; cobalt; embrittlement; creep; stress effect; aging treatment; precipitation; morphology.

\section{Introduction}

Recently, very much effort has been made on the development of the ferritic heat resisting steels used for the ultrasuper critical pressure power generating plants. ${ }^{1,2)} \mathrm{Fe}-$ $10 \% \mathrm{Cr}-\mathrm{W}$ alloys are basic alloys of such ferritic resisting steels. ${ }^{3)}$ It is well known that Laves phase forms in these ferritic steels and this phase is considered to contribute to the precipitation strengthening at high temperature but to induce the embrittlement at low temperature. ${ }^{4,5)}$ However, general features of the Laves phase precipitation behavior is not clarified. Particularly, creep stress effect on Laves phase precipitation behavior has not been clear. In the present research, stress effect on the precipitation behavior of the Laves phase at the early stage of aging and creep in the $\mathrm{Fe}-$ $10 \% \mathrm{Cr}-6 \% \mathrm{~W}-(\mathrm{Co})$ alloys has been investigated.

\section{Experimental Procedures}

The materials were melted in a vacuum induction furnace. The chemical composition of the materials is shown in Table 1. 3\% Co is added in the alloy B (6 W-3 Co) for the clarification of its effect, because the recently developed ferritic heat resisting steels contain $\mathrm{Co},{ }^{6)}$ while the details of the effect of Co has not been clarified except for the enhancement effect on the austenization at high temperature and the martensitic transformation on rapid cooling. $6 \% \mathrm{~W}$ is also added in the alloys to investigate the Laves phase $\left(\mathrm{Fe}_{2} \mathrm{~W}\right)$ precipitation behavior in the enhanced state, although the limit of $\mathrm{W}$ addition is suggested to be about $3 \%$ in the advanced ferritic heat resisting steels. ${ }^{3)}$

After hot rolling, specimens were solution treated at $1323 \mathrm{~K}$ for $3.6 \mathrm{ks}$ and water quenched. Aging treatment was carried out at 873 and $923 \mathrm{~K}$ for 1.0 to $3.6 \times 10^{3} \mathrm{ks}$.
Tensile stress of $80 \mathrm{MPa}$ was also loaded on the creep test specimens at 873 and $923 \mathrm{~K}$ for $7.2 \times 10^{2} \mathrm{ks}$ for the investigation of stress effect on the Laves phase precipitation behavior.

Vickers hardness (Load: 98N) measurement was performed after the aging treatment .Transmission electron microscopy (TEM) observation was also made after the aging treatment or the creep stress loading.

\section{Experimental Results and Discussion}

The Vickers hardness change during the aging treatment at 873 and $923 \mathrm{~K}$ is shown in Fig. 1. Small hardness peaks are observed after about 10 and $1.0 \mathrm{ks}$ aging at 873 and $923 \mathrm{~K}$, respectively, in both alloys A and B. After these small peaks, both alloys indicate large hardness increase. Miyahara et al. have already recognized a similar hardness change in the $\mathrm{Fe}-10 \% \mathrm{Cr}-\mathrm{Mo}$ alloys and shown that this phenomenon is related to the characteristics of the Laves phase precipitation behavior. $^{7-9)}$ That is, they have clarified that the small hardness peak is caused by the very fine disklike precipitates formed on the $\{100\}$ planes of the matrix before the bulky Laves phase formation and that the large hardness increase after the small hardness peak is due to the large volume of the bulky Laves phase precipitates. ${ }^{7-9)}$

Table 1. Chemical composition of the materials used. (mass\%)

\begin{tabular}{cccccccc}
\hline Alloy & $\mathrm{C}$ & $\mathrm{Si}$ & $\mathrm{Mn}$ & $\mathrm{S}$ & $\mathrm{Cr}$ & $\mathrm{W}$ & $\mathrm{Co}$ \\
\hline Alloy A (6W) & 0.0014 & 0.03 & 0.003 & 0.0024 & 9.89 & 5.86 & 0.09 \\
\hline Alloy B (6W-3Co) & 0.0013 & 0.02 & 0.0019 & 0.0021 & 10.16 & 6.16 & 3.03 \\
\hline
\end{tabular}




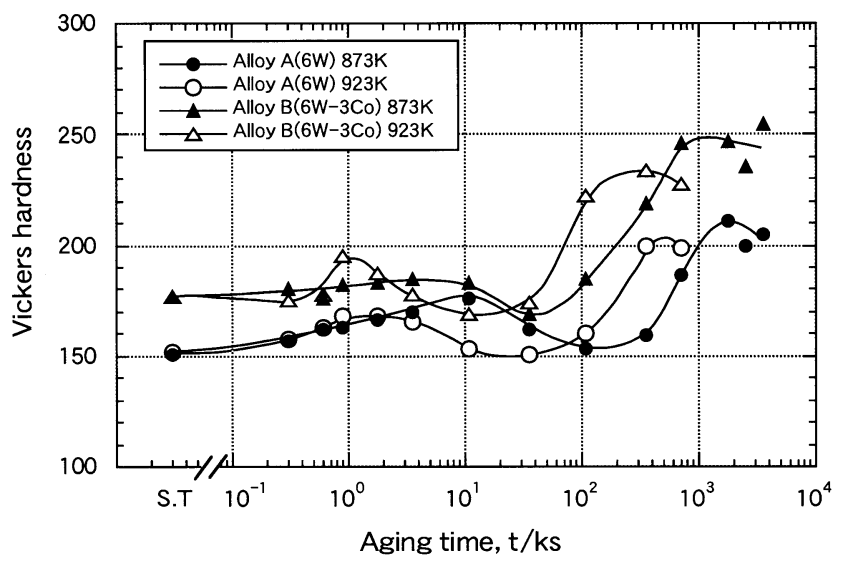

Fig. 1. Vickers hardness (load: $98 \mathrm{~N}$ ) change during the aging treatment at $873 \mathrm{~K}$ and $923 \mathrm{~K}$ of alloys $\mathrm{A}(6 \mathrm{~W})$ and $\mathrm{B}$ $(6 \mathrm{~W}-3 \mathrm{Co})$.

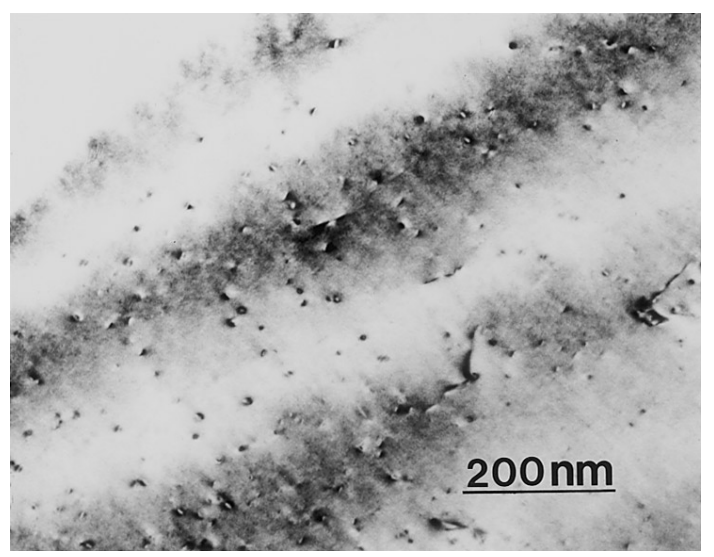

Fig. 2. Tiny precipitates in the alloy A (6W) aged for $10.8 \mathrm{ks}$ at $873 \mathrm{~K}$.

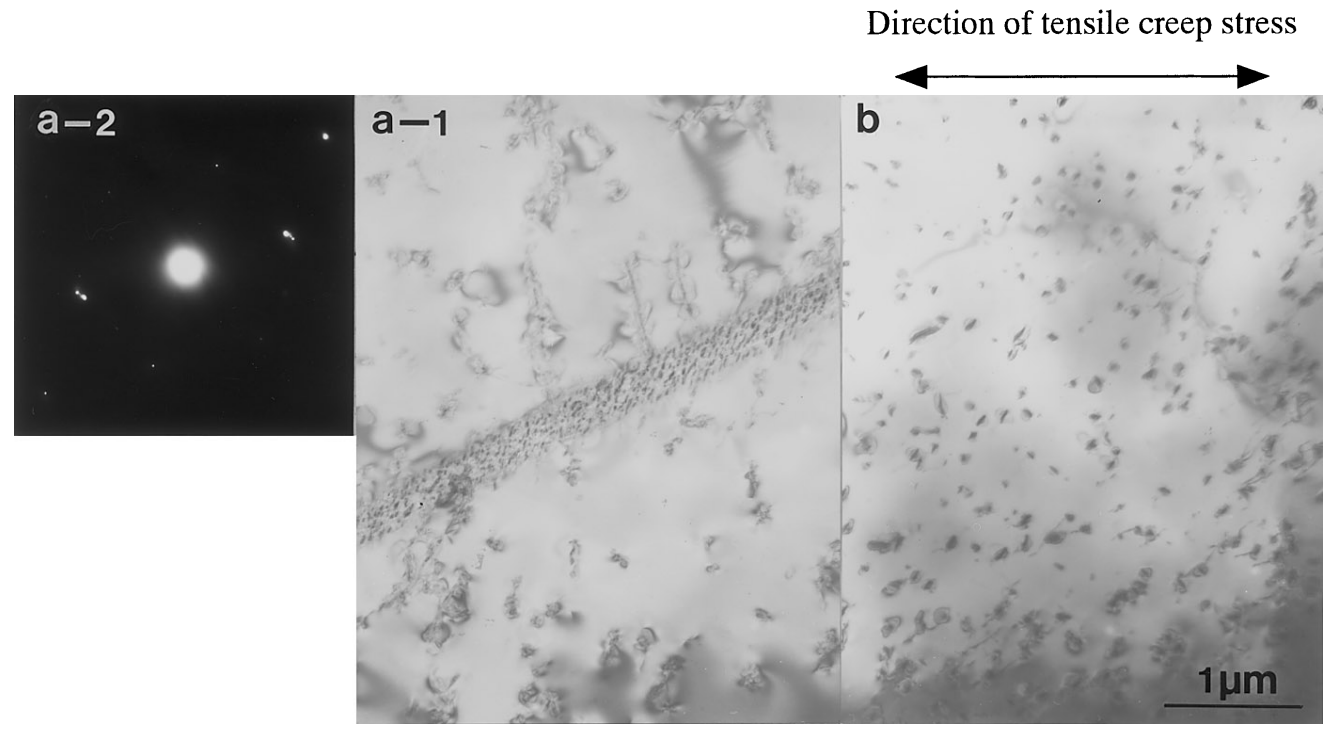

Fig. 3. TEM observation on the Laves phase precipitation in the alloy $A(6 \mathrm{~W})$.

(a-1) aged at $873 \mathrm{~K}$ for $7.2 \times 10^{2} \mathrm{ks}$, (a-2) selected area diffraction pattern from the subboundary in the photo. (a-1), (b) crept with the load of $80 \mathrm{MPa}$ at $873 \mathrm{~K}$ for $7.2 \times 10^{2} \mathrm{ks}$.

TEM observation of the present research also suggests that the hardness change of the alloys A and B is due to the same mechanism of the Laves phase precipitation behaviors. A TEM photograph on the alloy A aged at $873 \mathrm{~K}$ for $10.8 \mathrm{ks}$, which indicates the first small hardness peak, is shown in Fig. 2. Coherent strain is observed in the matrix around the tiny precipitates and the small hardness peak is considered to be caused by these tiny precipitates.

Figures 3 and 4 show the Laves phase formation in the alloys $\mathrm{A}$ and $\mathrm{B}$, which are aged at $873 \mathrm{~K}$ for $7.2 \times 10^{2} \mathrm{ks}$ under the load of creep stress of $80 \mathrm{MPa}$ or at unloaded state. $80 \mathrm{MPa}$ is about one half of $0.2 \%$ proof strength of the alloys A and B at $873 \mathrm{~K}$. The creep stress effect on the Laves phase precipitation is clearly observed in these figures. Figure 3(a-1) shows that, in the alloy A aged at the stress unloaded state, very tiny precipitates are formed on the dislocation network in a subboundary which is certified by a diffraction pattern (Fig. 3(a-2)) and that the precipitates within the grains are also formed only on the dislocations. On the other hand, as shown in Fig. 3(b), slightly larger precipitates are formed uniformly in the matrix under the creep stress loading. Accordingly, it can be seen from Fig. 3 that the creep stress enhances the Laves phase precipitation at the early stage of aging. Figure 4 also shows that the creep stress enhances the Laves phase formation in the alloy B. Furthermore, comparing Fig. 4 with Fig. 3. It is seen that the addition of Co enhances the precipitation of the Laves phase.

Quantitative analysis for the number density of the Laves phase precipitates has been made on the alloys A and B aged or crept at $873 \mathrm{~K}$, using TEM observation results, as shown in Fig. 5. Specimen thickness of TEM observed area was obtained from the extinction distance and contour. The number density per unit volume, $N_{\mathrm{v}}\left(\mathrm{m}^{-3}\right)$, of the Laves phase precipitates can be obtained from the slope of the line shown in Fig. 5 and the $N_{\mathrm{v}}$ values are got as followings, the aged alloy $\mathrm{A} ; 2.4 \times 10^{10} \mathrm{~m}^{-3}$, the crept alloy $\mathrm{A} ; 4.7 \times$ $10^{10} \mathrm{~m}^{-3}$, the aged alloy $\mathrm{B} ; 3.4 \times 10^{10} \mathrm{~m}^{-3}$ and the crept alloy $B ; 4.9 \times 10^{10} \mathrm{~m}^{-3}$. These values indicate that the creep stress increases the number density of the Laves phase precipitates. Average precipitates size in the crept specimen is also slightly larger than that in the aged specimens, as 
shown in Figs. 3 and 4. Accordingly, it is certified quantitatively that the creep stress enhances the Laves phase precipitation in the alloys A and B aged or crept at $873 \mathrm{~K}$. The above $N_{\mathrm{v}}$ analysis results also indicate that Co has small effect to increase the number density of Laves phase precipitates, but the comparison between Figs. 3 and 4 shows that Co has a effect to enhance the growth of the Laves phase precipitates. Accordingly, it can be concluded that Co has a effect to enhance the preipitation of the Laves phase in the stress loaded state, at lease, at the early stage of creep deformation at $873 \mathrm{~K}$.

Figure 6 shows the Laves phase in the alloy B aged at $923 \mathrm{~K}$ for $7.2 \times 10^{2} \mathrm{ks}$ under the creep stress of $80 \mathrm{MPa}$ or at stress unloaded state. In Fig. 6, slightly darker image of the Laves phase particles, that is, thicker particles of the Laves phase are observed in the crept specimen than in the aged specimen. Accordingly, this figure also shows that creep stress enhances the Laves phase precipitation at $923 \mathrm{~K}$. Although the mechanism of such creep stress effect on the

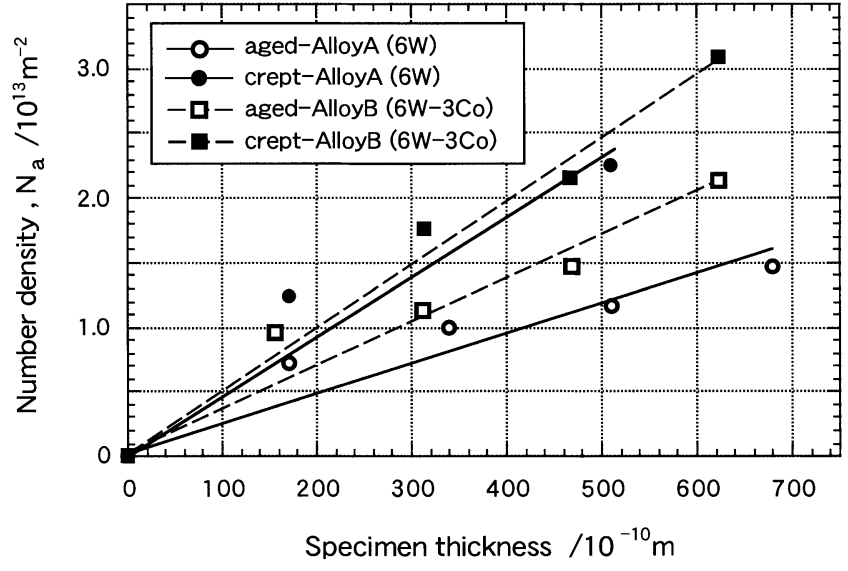

Fig. 5. Specimen thickness dependences of number density per unit area $\left(\mathrm{N}_{\mathrm{a}} / \mathrm{m}^{-2}\right)$ of the Laves phase precipitates in the alloys $\mathrm{A}(6 \mathrm{~W})$ and $\mathrm{B}(6 \mathrm{~W}-3 \mathrm{Co})$ aged or crept at $873 \mathrm{~K}$ for $7.2 \times 10^{2} \mathrm{ks}$

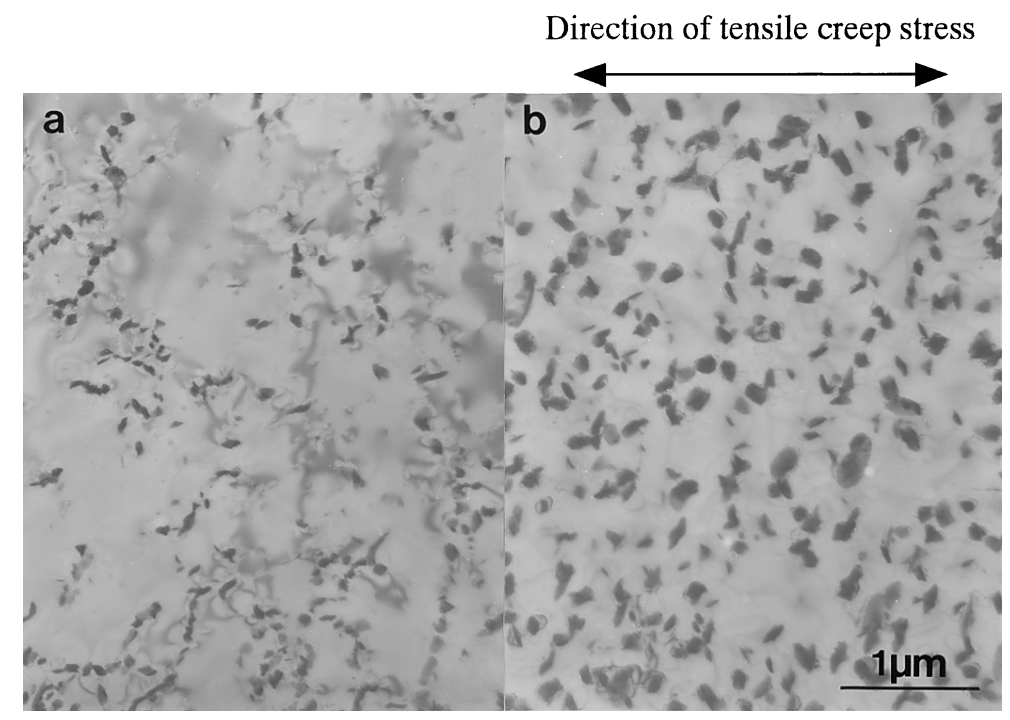

Fig. 4. TEM observation on the Laves phase precipitation in the alloy $\mathrm{B}(6 \mathrm{~W}-3 \mathrm{Co})$.

(a) aged at $873 \mathrm{~K}$ for $7.2 \times 10^{2} \mathrm{ks}$, (b) crept with the load of $80 \mathrm{MPa}$ at $873 \mathrm{~K}$ for $7.2 \times 10^{2} \mathrm{ks}$.

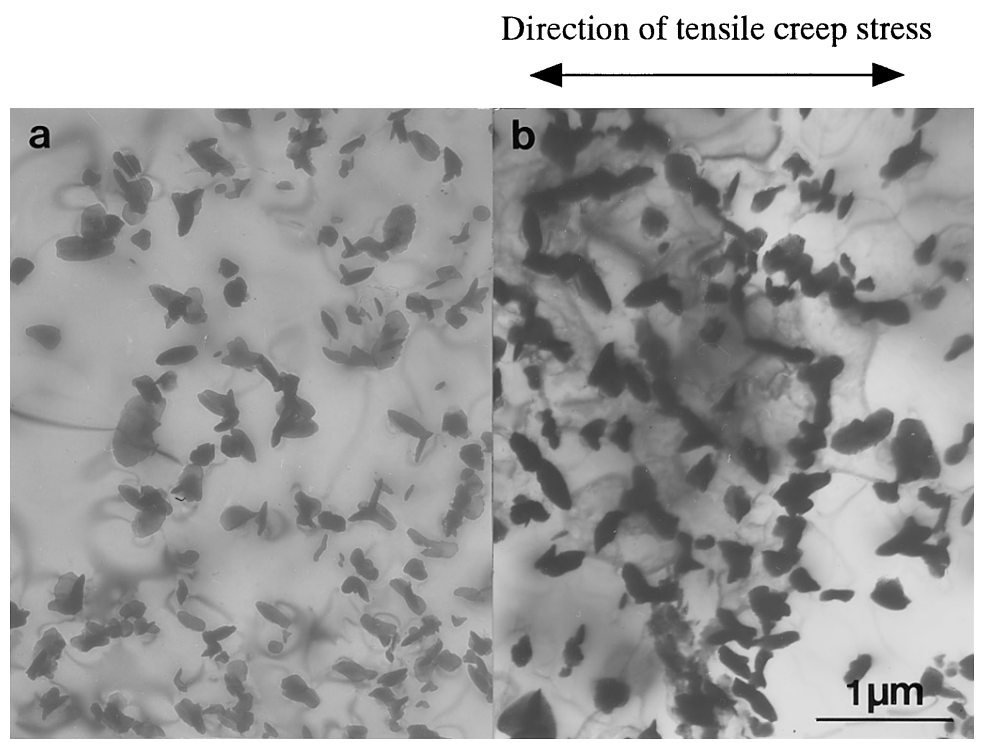

Fig. 6. TEM observation on the Laves phase precipitation in the alloy $\mathrm{B}(6 \mathrm{~W}-3 \mathrm{Co})$.

(a) aged at $923 \mathrm{~K}$ for $7.2 \times 10^{2} \mathrm{ks}$, (b) crept with the load of $80 \mathrm{MPa}$ at $923 \mathrm{~K}$ for $7.2 \times 10^{2} \mathrm{ks}$. 
Laves phase precipitation cannot be clearly understood at the present time, the dragging effect of dislocation for $\mathrm{W}$ atoms at the stress loading is considered to be one of important factors for the enhancement of precipitation and growth of the Laves phase.

\section{Conclusions}

The creep stress effect on the Laves phase formation behavior in $\mathrm{Fe}-10 \% \mathrm{Cr}-6 \% \mathrm{~W}$ alloys has been investigated. The creep stress enhances the Laves phase formation during the aging at $873 \mathrm{~K}$ and $923 \mathrm{~K}$. One of the mechanisms for such clear creep stress effect is considered to be due to the dragging effect of dislocations for $\mathrm{W}$ atoms, which enhances the movement of $\mathrm{W}$ atoms.

\section{REFERENCES}

1) F. Masuyama: Advanced Heat Resistant Steel for Power Generation, ed. by R. Viswanathan and J. Nutting, The University Press, Cambridge, (1999), 33.

2) D. V. Thornton and K. H. Mayer: Advanced Heat Resistant Steel for Power Generation, ed. by R. Viswanathan and J. Nutting, The University Press, Cambridge, (1999), 349.

3) K. Asakura, Y. Kawabuchi and T. Fujita: Tetsu-to-Hagané, 75 (1989), 1209.

4) T. Fujita: Tetsu-to-Hagané, 76 (1990), 1053.

5) Y. Hosoi, N. Wade, S. Kunimitsu and T. Urita: Tetsu-to-Hagané, 76 (1990), 1116.

6) K. Hidaka, Y. Fukui, S. Nakamura, R. Kaneko, Y. Tanaka and T. Fujita: Advanced Heat Resistant Steel for Power Generation, ed. by R. Viswanathan and J. Nutting, The University Press, Cambridge, (1999), 418.

7) K. Miyahara, J. H. Hwang and Y. Shimoide: Scr. Metall. Mater., 32 (1994), 1917.

8) K. Miyahara, J. H. Hwang and Y. Shimoide: Tetsu-to-Hagané, 81 (1995), 65.

9) K. Miyahara, J. H. Hwang, Y. Shimoide, T. Iwamoto and Y. Hosoi: $J$. Jpn. Inst. Met., $\mathbf{5 9}$ (1995), 512. 